\title{
Navigating Global Online Market Places (GOMPs) An ADR Perspective
}

Baiyere, Abayomi; Jensen, Thomas; Fischer, Louise Harder ; Staykova, Kalina; Wessel, Michael; Hedman, Jonas

\author{
Document Version \\ Accepted author manuscript
}

Published in:

ICT Unbounded, Social Impact of Bright ICT Adoption

DOI:

10.1007/978-3-030-20671-0 36

Publication date:

2019

License

Unspecified

Citation for published version (APA):

Baiyere, A., Jensen, T., Fischer, L. H., Staykova, K., Wessel, M., \& Hedman, J. (2019). Navigating Global Online Market Places (GOMPs): An ADR Perspective. In Y. Dwivedi, E. Ayaburi, R. Boateng, \& J. Effah (Eds.), ICT Unbounded, Social Impact of Bright ICT Adoption: Proceedings of FIP WG 8.6 International Conference on Transfer and Diffusion of IT, TDIT 2019 (pp. 529-535). Springer. IFIP Advances in Information and Communication Technology No. 558 https://doi.org/10.1007/978-3-030-20671-0_36

Link to publication in CBS Research Portal

\section{General rights}

Copyright and moral rights for the publications made accessible in the public portal are retained by the authors and/or other copyright owners and it is a condition of accessing publications that users recognise and abide by the legal requirements associated with these rights.

Take down policy

If you believe that this document breaches copyright please contact us (research.lib@cbs.dk) providing details, and we will remove access to the work immediately and investigate your claim. 


\section{Navigating Global Online Market Places (GOMPs): An ADR Perspective}

\section{Abayomi Baiyere, Thomas Jensen, Louise Harder Fischer, Kalina Staykova, Michael Wessel, and Jonas Hedman}

Article in proceedings (Accepted version*)

\section{Please cite this article as:}

Baiyere, A., Jensen, T., Fischer, L. H., Staykova, K., Wessel, M., \& Hedman, J. (2019). Navigating Global Online Market Places (GOMPs): An ADR Perspective. In Y. Dwivedi, E. Ayaburi, R. Boateng, \& J. Effah (Eds.), ICT Unbounded, Social Impact of Bright ICT Adoption: Proceedings of FIP WG 8.6 International Conference on Transfer and Diffusion of IT, TDIT 2019 (pp. 529-535). Cham: Springer. IFIP Advances in Information and Communication Technology, No. 558 https://doi.org/10.1007/978-3-030-20671-0_36

This is a post-peer-review, pre-copyedit version of an article published in IFIP Advances in Information and Communication Technology. The final authenticated version is available online at:

DOI: https://doi.org/10.1007/978-3-030-20671-0_36

* This version of the article has been accepted for publication and undergone full peer review but has not been through the copyediting, typesetting, pagination and proofreading process, which may lead to differences between this version and the publisher's final version AKA Version of Record. 


\title{
Navigating Global Online Market Places (GOMPs) - An ADR Perspective
}

\author{
Abayomi Baiyere, Thomas Jensen, Louise Fischer Kalina Staykova, \\ Michael Wessel, and Jonas Hedman \\ Copenhagen Business School \\ Denmark \\ aba.digi@cbs.dk, tj.digi@cbs.dk, lhf.digi@cbs.dk, kss.digi@cbs.dk,mw.digi@cbs.dk, \\ je.digi@cbs.dk
}

\begin{abstract}
Global Online Market Places (GOMPs), such as Amazon, Alibaba, Otto, transforms ecommerce. We are moving away from a world of many ecommerce stores to a world populated by a few oligopolies. This create a new competitive situation, not only for the individual frim, but also for countries. Despite the established importance of export to a nation's economy and the proliferation of the internet today, there are still many companies grappling with taking advantage of the possibilities of e-export. This study is aimed at designing a solution and developing an intervention to mitigate the challenges faced by such companies in Denmark. This research in progress paper reports on the initial activities of the design of a platform intended to be the hub for connecting companies to multiple online market places. This paper sets the frame for the subsequent design, development and evaluation efforts as well as learnings for this research project. Our study extends the conventional view of ADR from a research approach with an organizational purview to one that is amenable to providing practically relevant solutions to national issues.
\end{abstract}

The abstract should summarize the contents of the paper in short terms, i.e. 150250 words.

Keywords: Design science research, platform, online marketplaces, e-commerce

\section{Introduction}

In recent years, global online marketplaces (GOMPSs), have been transforming global trade. Renown examples of this are Amazon and Alibaba to mention a few. The value of export of goods and services between nations has been long established and the potential remains huge for both the companies and nations involved (Hertel and Keeney 2006). According to Porter (1990) - "A nation's competitiveness depends on the capacity of its industry to innovate and upgrade. Companies gain advantage against the world's best competitors because of pressure and challenge. They benefit from having 
strong domestic rivals, aggressive home-based suppliers, and demanding local customers."

GOMPs have become a potent avenue for carrying out exports today (Albaum and Duerr 2008). Despite the acclaimed value of exports and the pervasiveness of the internet and digital technologies, there are still a large number of companies that have not been able to take advantage of the opportunities of e-exports of these GOMPs. According to a recent study in Denmark, only about one in ten Danish companies export digitally, while the percentage of companies taking advantage of e-export is at an average of eight percent (Christensen 2017). Due to the evolutions of technology and GOMPs in particular this premise does not hold any longer. In addition, small firms face the risk of being left behind. Therefore, from a national perspective it is critical to help firms to sell on GOMPS. We thus engage in developing a public good platform that enables firms to access and sell on GOMPs.

The paucity of companies carrying out e-export activities can be roughly traced to lack of knowledge and financial resources. We have identified some of the key challenges and this research in progress outlines a preliminary report of the planned action design research (ADR) study for mitigating against these challenges and boosting the presence of Danish companies in the e-export arena. Some of the barriers to achieving e-export stem from issues that can be classified into a class of problems for which a design outcome can provide tenable solutions. A major challenge faced by these companies stem the fact that there are multiple global online marketplaces - GOMPs. Example of GOMPs includes large ones such as Amazon and Alibaba, and a range of not so well known GOMPs such as Marktplaats and Rakuten, among many others. The challenge is that each GOMP has its own boundary resources () which further complicates this for intending companies wishing to go global. In essence, a key challenge for most companies is that they have issues in identifying and leveraging the multitude of GOMPs for e-export out there, as well as how to connect to these platforms successfully.

Additionally, this study is positioned to shift the locus of ADR studies by demonstrating that the principles of ADR approach can be useful beyond the traditional organizational context. In this study, we intend to extend the utility of ADR to demonstrate its value in the design and intervention of national issues as well by developing public goods to the benefit of society. This research in progress paper takes an ADR perspective and reports the preliminary design and intervention approach planned for helping companies minimize the barriers to e-export. The idea for the study originates from the national foundation of Danish industrial companies and an associated fund. They recognize that e-export especially business to business (B2B) is important for firms in today's competitive landscape. They found that the nation in 2016 ranked rather low compared to other nations on the share of export for B2B via on-line channels. These observations formed the background and motivation for embarking on this study. 


\section{$2 \quad$ Method}

Our study employs the principles of ADR as articulated by Sein et al. (2010). ADR is an appropriate methodological choice in situations where the intention is to generate prescriptive design knowledge via the creation and evaluation of an IT artifact (Gregor and Hevner 2013). In contrasts with action research and design research, ADR deals with two fundamental research issues (Sein et al. 2010)). Firstly, it is a relevant approach when there is an objective to address research problems by intervening and evaluating the impact of the intervention. Secondly, it is additionally relevant when there is a need to build and evaluate an IT artifact that solves a class of problems that is typified by the issue at hand. These pivotal points in the conduct of an ADR study makes it a research approach that places emphasis on the building, intervention and evaluation of an IT artifact that is positioned to contribute both theoretical insights as well as practically relevant solutions to the actors concerned (Sein et al 2011). Consequently, our research can be considered as an engaged scholarship (van de Ven 2007) where scholars engage with the industry to create synergies and new knowledge. ADR (Sein et al. 2011) is a recognized approach in information systems research that can be leveraged to generate useful knowledge for both practitioners and academics.

In consonance with the requirements of an ADR study, this research can be structured in four stages. Firstly, the problem formulation stage of the study gets its premise from the observed challenges of e-export by Danish companies. Our study is planned as a four years longitudinal study with support from the relevant actors for which the class of problem bears relevance. Secondly, the build, intervention and evaluation stage, is structured to involve the design and development of a platform that connects multiple GOMPs and provides seamless access to Danish companies. The emerging artifact from this process would be evaluated based on the capacity of the artifact to mitigate the highlighted challenges as well as the number of companies that can effectively begin to use the platform to exploit the benefits of e-export. Thirdly, the reflection and learning phase is structured to happen concurrently with all the other stages of the project. Considering the longitudinal nature of the project, it is expected that there will be multiple opportunities for learning and reflection during iterations across and within the ADR stages (Mullarkey and Hevner 2015). Lastly, the formalizing of learning stage is expected to follow the recommendations of van Aken (2004) to enable us abstract from the situated learning to general solution concepts that are transferrable to a class of problems. In general, our research approach for this study follows the ADR method as laid out by Sein et al. (2011), which refers to an iterative development process where knowledge and development mutually influence each other.

Problem

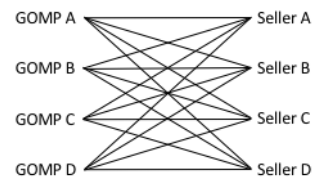

Solution

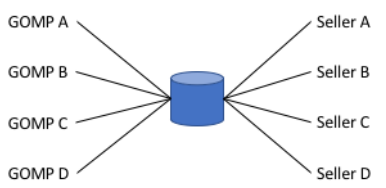




\section{Intended Artifact Design (Choices and Justifications)}

There are multiple intended designs, including a connector that seamlessly via APIs connect the firm's ERP system or web shops with the platform which again connect to the selected GOMPs and boundary resources, such as Open-API, SDK, documentation and tutorials. The artifact is a platform with the capacity to enable initially few firms to connect to one or more GOMPs, see figure 1 . The intention is to gradually connect to more firms and more GOMPs after a pilot of one to three GOMPs. By year three of the project the objective is to have at least 100 firms connected with about 10 major GOMPs. Furthermore, there should be actual export activities taking place via the platform after this initiative. However, the number of ERP systems are limited to 3 which covers a relatively high share of the Danish firms.

To facilitate the individual firm's decision a range of tools are planned to be designed which included 1) decision support tool, 2) mapping of global online marketplaces, and 3 ) a tool to evaluate the firms maturity. The initial activity was to invite vendors that potential can deliver the platform, accordingly five vendors were invited to propose their solution and offerings. Three vendors choose to pitch their solution and offer. Each vendor received an invitation to become a partner in the platform and to pitch their candidate. They then received a description of the design and expected deliverable.

With respect to the design elements for the expected deliverable, a functioning eexport platform meeting the following design principles was requested: Synchronizing and displaying product data from Danish firms on GOMP, including connectivity to at least three GOMP, and connectivity /APIs to the top three ERP systems and the top three e-commerce systems. Furthermore, since the aim of the project is to support Danish firms, in the most efficient and effective way, the design of the platform and its connectors should be well documented based on open APIs and it should include software development kit (SDK), example code, tutorials, support, and training material. Thus, the platform and its connectors with associated documentation should be at the level that an independent IT consultant should be able to set-up the integration between Danish firms and selected GOMPs. The platform should be up and running by May 2019 and available for Danish firms. After May 2019, we foresee a process with continuous improvements, potential updates of the connectors towards the GOMP, and support to firms. By the end of the project it should have at least 100 companies selling over the e-export platform.

Additionally the vendors were asked to address the following non-design and practical considerations:

1. Indicate whether they believe it is feasible to have the platform up and running by May 2019.

2. Time and cost estimations of delivering the platform, connectors and associated material. They were to include a description of how they reached the cost and time estimates, including hourly rate and other costs.

3. Some details on experience of developing platform and open-API with some references or cases. 
4. Experience of working together with universities.

5. In addition, expression of how they see the long-term survival of the platform. Or in other words its business models including its revenue sources, operating cost, and ownership after the projects ends in 2021. For instance, how much should it cost for Danish firms to enroll in the future.

Each of the three vendors delivered impressive pitches and detailed solution descriptions. The evaluation committee compared the three companies, their experiences and references, their pitches and their proposed design and solutions. There were significant variances among them both in capabilities, experiences, solutions proposed and the estimated costs. In the end one of the prototype designs with greater affinity to the design solutions identified by the research team as best fitting to address the class of problems was selected. The next phase of the study is the actual development which is expected to happen with several iterations as more knowledge is gathered and as the understanding of the problem space and its solution possibility develops. This phase is expected to be followed by a number of tests and pilot implementations to observe the extent to which the initial design assumptions hold true in addressing the issues. Some of the areas of potential improvement include:

- Identification of approach to connect to each GOMP's API and web services

- Simple and effective user interface designs to reduce complexity

- Possibility to connect via plug and play to the companies ERP systems

- Ability for participating companies to promote their products across several GOMPs with minimal effort.

- Extendability and scalability of the platform to more GOMPs

- Adaptiveness to unilateral changes of the API's and web services of GOMPs

\section{$4 \quad$ Planned Evaluation Strategy}

The overall evaluation criterias for the project are given by the sponsoring fund on behalf on the association of Danish industrial firms. As stipulated by the funding actor in this project, the overall success criteria for the project and the designed platform would be measured based on the following:

- Danish companies should double the volume of e-exports.

- New knowledge and new e-export tools for Danish companies.

- Reduce Danish companies' costs to begin e-exports by over 1.3 million Euros.

- 100 companies participating and should have carried out about 30 million Euros worth of transaction via the platform.

- At least 8 research publications should be published.

- At least 8 conferences, seminars and workshops should be documented. 
The evaluation of the aforementioned criteria will be conducted as the project evolves over time. At the same time the success for each firm will also be evaluated. From an earlier pilot, the first firms are selling their products on the platform and accordingly metrics for the measurement of success has been developed in accordance. The first firm on the platform with connections to 5 GOMPs has been live with online e-shops online since November 1st and up to today (4 month) and therefore we have chosen to compare 01.11-01.03 2015/2016 and 2016/2017. Measured on the total of the 5 GOMPs, revenue has increased by $59.8 \%$ by the following: 1) .de: $37.5 \%$ 2) fr: $70.2 \%$ 3) .it: $139.5 \%$ 4) .uk: $-6.7 \%$ and 5) .es: $58.4 \%$. The increase is due to the fact that the firm has gained more products online due to integration, as it has not been possible to maintain such large quantities of products in the past. In order to put the figures in perspective, it is expected that this year will be set up on a 2-digit million revenue. At the time of writing, the publication has processed more than 5,000 orders and more than 80,000 products for the firm. The results are measured on revenue through statistical tools of the GOMPs. The aim of this subsequent implementations is to have at least 100 companies and 10 major GOMPS, and to effectively monitor the increase in number of transactions. Furthermore, the evolution of the maturity of participating firms to perform e-export via GOMPs is to be assessed and a measure for that is also under development.

\section{Expected Learnings/Outcomes}

It is expected that the study should afford us the opportunity to abstract several theoretical and practically relevant knowledge. Chief among these possible contributions are:

- The design and development of an IT artifact (the multichannel GOMP connectore platform) that faciliates e-export by mitigating the complexities of dealing with several GOMPS.

- The articulation of the key design principles that are essential and trasnferrable as design solutions to a class of problems regarding the design of national e-export platforms.

\section{Conclusion}

This research in progress study outlines the plans to solve the challenges of e-export that is limiting many Danish companies from taking full advantage of the benefits of eexport via GOMPs. The study takes its methodological premise from the principles of ADR to position its contribution as a designed artifact as well as an intervention that should collectively yield practical solutions and theoretical insights to the challenges of e-exports. We contend that it is important to study this because; a) e-export is important in todays competitive landscape both from a nation's viewpoint as well as the respective companies perspective. b) The problem class that this study aims to address is general and affects several nations. Hence, eliminating the barriers to achieving e-export is a pertinent research and societally relevant endeavour. 
In essence, our study has the potential to address the bottleneck of companies having troubles in identifying and leveraging the multitude of e-export platforms out there. The planned study is aimed to come up with a design solution that is encapsulated in the form of a digital platform for interacting with multiple GOMPs. With this approach, it is expected that each firm does not have to set up and maintain APIs for each of the global online marketplaces which they intend to sell their markets on, thereby eliminating one of the major barrier for their attempts at e-export.

\section{References}

1. Albaum, G., \& Duerr, E. (2008). International marketing and export management. Pearson Education.

2. Christensen J. (2017) Danish companies do not make great use of e-exports. DI Business

3. Davison, R., Martinsons, M. G., \& Kock, N. (2004). Principles of canonical action research. Information systems journal, 14(1), 65-86.

4. Gregor, S., \& Hevner, A. R. (2013). Positioning and presenting design science research for maximum impact. MIS quarterly, 37(2).

5. Hertel, T. W., \& Keeney, R. (2006). What is at stake: the relative importance of import barriers, export subsidies, and domestic support. Agricultural Trade Reform and the Doha Development Agenda, 37.

6. Hevner, A. R., March, S. T., Park, J., \& Ram, S. (2004). Design science in information systems research. MIS quarterly, 28(1), 75-105.

7. Mullarkey, M. T., \& Hevner, A. R. (2015, May). Entering action design research. In International Conference on Design Science Research in Information Systems (pp. 121-134). Springer, Cham.

8. Sein, M. K., Henfridsson, O., Purao, S., Rossi, M., \& Lindgren, R. (2011). Action design research. MIS quarterly, 37-56.

9. Van de Ven, A. H. (2007). Engaged scholarship: a guide for organizational and social research: a guide for organizational and social research: Oxford University Press.

10. Van Aken, J. E. 2004. "Management Research Based on the Paradigm of the Design Sciences: The Quest for Field-Tested and Grounded Technological Rules," Journal of Management Studies (41:2), pp. 219-24

Acknowledgements: This work was carried out with the support by the "E-eksport via online markedspladser" project via a grant from the Danish Industry Foundation (grant number 2017-0165) and by the Department of Digitalization at Copenhagen Business School. 